\title{
Collagen XIII Induced in Vascular Endothelium Mediates $\alpha 1 \beta 1$ Integrin-Dependent Transmigration of Monocytes in Renal Fibrosis
}

\author{
Jameel Dennis, ${ }^{*}$ Daniel T. Meehan, ${ }^{*}$ \\ Duane Delimont, ${ }^{*}$ Marisa Zallocchi, ${ }^{*}$ \\ Greg A. Perry, ${ }^{\dagger}$ Stacie O'Brien, ${ }^{*}$ Hongmin Tu, ${ }^{\neq}$ \\ Taina Pihlajaniemi, ${ }^{\star}$ and Dominic Cosgrove* \\ From the Department of Genetics, ${ }^{*}$ Boys Town National Research \\ Hospital, Omaha, Nebraska; the Department of Immunology, ${ }^{\dagger}$ \\ Creighton University, Omaha, Nebraska; the Oulu Center for \\ Cell-Matrix Research, ${ }^{\ddagger}$ Biocenter Oulu, the Department of \\ Medical Biochemistry and Molecular Biology, Institute of \\ Biomedicine, University of Oulu, Oulu, Finland
}

\begin{abstract}
Alport syndrome is a common hereditary basement membrane disorder caused by mutations in the collagen IV $\alpha 3, \alpha 4$, or $\alpha 5$ genes that results in progressive glomerular and interstitial renal disease. Interstitial monocytes that accumulate in the renal cortex from Alport mice are immunopositive for integrin $\alpha 1 \beta 1$, while only a small fraction of circulating monocytes are immunopositive for this integrin. We surmised that such a disparity might be due to the selective recruitment of $\alpha 1 \beta 1$-positive monocytes. In this study, we report the identification of collagen XIII as a ligand that facilitates this selective recruitment of $\alpha 1 \beta 1$ integrin-positive monocytes. Collagen XIII is absent in the vascular endothelium from normal renal cortex and abundant in Alport renal cortex. Neutralizing antibodies against the binding site in collagen XIII for $\alpha 1 \beta 1$ integrin selectively block VLA1-positive monocyte migration in transwell assays. Injection of these antibodies into Alport mice slows monocyte recruitment and protects against renal fibrosis. Thus, the induction of collagen XIII in endothelial cells of Alport kidneys mediates the selective recruitment of $\alpha 1 \beta 1$ integrin-positive monocytes and may potentially serve as a therapeutic target for inflammatory diseases in which lymphocyte/monocyte recruitment involves the interaction with $\alpha 1 \beta 1$ integrin. ( $A m J$ Pathol 2010, 177:2527-2540; DOI: 10.2353/ajpath.2010.100017)
\end{abstract}

Alport syndrome is a relatively common ( 1 in 5000) hereditary basement membrane disorder caused by mutations in the collagen IV $\alpha 3, \alpha 4$, or $\alpha 5$ genes. ${ }^{1-3}$ The disease manifests with progressive renal disease associated with hearing loss and retinal flecks. There are several models for Alport's Syndrome including a collagen IV $\alpha 3$ knockout mouse. ${ }^{4,5}$ In the 129 Sv Alport mouse model, animals develop glomerular and interstitial fibrosis followed by end stage renal failure between 8 and 9 weeks of age. Increased extracellular matrix deposition, mesangial matrix expansion, impaired glomerular filtration, scarring and tubular atrophy observed in this model correlate with Alport's syndrome pathogenesis reported in humans. In this model two biochemical pathways are known to contribute to disease progression. The first pathway requires transforming growth factor- $\beta$, while the second is $\alpha 1$-integrin dependent. ${ }^{6}$

Monocytes express transforming growth factor- $\beta$ which facilitates myofibroblast accumulation and matrix deposition in Alport mice. Monocytes also express matrix metalloproteinases and associated proteins capable of degrading tubular basement membranes and promoting tubular epithelial cell death. ${ }^{7}$ These findings suggest that monocytes are of principal importance in promoting scarring and tubular atrophy in chronic renal fibrosis. This connection has been corroborated in other models of renal fibrosis. ${ }^{8,9}$ Thus the cellular mechanisms that facilitate transmigration and proliferation of interstitial monocytes are important factors in promoting the progression of interstitial disease.

Supported by R01 DK55000 to DC and tobacco settlement funds from the State of Nebraska, Health Sciences Council of the Academy of Finland (115237), the Sigrid Juselius Foundation and the Finnish Cancer Foundation (T.P.)

Accepted for publication July 21, 2010

None of the authors declared any relevant financial relationships.

Current address of J.D.: Virginia Commonwealth University, Richmond, VA

Address reprint requests to Dominic Cosgrove, Ph.D., Boys Town National Research Hospital, 555 North $30^{\text {th }}$ St., Omaha, NE 68131. E-mail: Cosgrove@boystown.org. 
In an earlier report, we showed that nearly all of the monocytes in Alport kidneys express $\alpha 1 \beta 1$ integrin. ${ }^{10}$ We also have shown that integrin $\alpha 1$-null Alport mice live nearly twice as long as Alport mice, an observation that correlates well with a marked reduction in interstitial monocyte accumulation. ${ }^{6,10}$ Alpha1beta1 integrin (also known as VLA-1, or very late antigen 1) mediates collagen dependent cell proliferation and adhesion. ${ }^{11,12}$ However, a role for $\alpha 1 \beta 1$ integrin in transmigration of inflammatory cells across the microvascular barrier into the interstitial spaces has not been directly demonstrated.

Monocyte and lymphocyte transmigration into the interstitial space is a principal event underlying both acute and chronic inflammatory response mechanisms. ${ }^{13}$ Many aspects of the cellular events underlying the initiation and progression of monocyte efflux have been elaborated in recent years, as these pathways are central to pathobiology of many inflammatory diseases. The initiation of the inflammatory response involves cellular expression of chemokines and inflammatory cytokines, which have profound effects on adjacent cells. The vascular and capillary endothelial cells respond by up-regulating expression of selectins and intercellular adhesion molecules. ${ }^{14,15}$ The selectins loosely adhere to lymphocytes and monocytes resulting in a "slow rolling" effect that can be visualized directly using intravital microscopy. ${ }^{16}$ Intercellular adhesion molecules and related inducible endothelial cell surface ligands provide the substrate for firm adhesion through interactions with the integrin family of heterodimeric receptors on the surface of the monocytes. ${ }^{13}$ Firm adhesion results in monocyte activation, inducing the expression of proteins needed to degrade the capillary basal lamina, allowing invasion into the interstitial space. ${ }^{17,18}$ The activated monocyte produces additional chemokines and cytokines, which further accelerate monocyte recruitment and the progression of the inflammatory response.

Research aimed at defining the specific cellular mechanisms underlying monocyte and lymphocyte recruitment has been prolific. The discovery of integrins, a vastly important family of cell surface receptors that mediate adhesion, cell migration and signal transduction, resulted from studies aiming to identify the adhesion receptors on peripheral blood monocytes and lymphocytes, as well as their cognate ligands on activated vascular endothelium. ${ }^{19}$ Monoclonal antibodies that block the interaction of these cells with endothelial cell surface receptors have emerged as potentially effective therapeutic approaches for treating chronic inflammatory diseases such as multiple scleroses and psoriasis. A large number of such agents are currently in various stages of preclinical and clinical trials. ${ }^{20,21}$

The $\alpha 1$-integrin heterodimerizes only with $\beta 1$-integrin. The heterodimer is found in the plasma membrane of a variety of cell types, and is widely viewed as a collagen binding integrin, although binding to other matrix molecules has been demonstrated. ${ }^{22,23}$ We used a monocyte-specific cell trafficking assay to determine whether selective transmigration of $\alpha 1 \beta 1$ integrin-positive monocytes contributes to the accumulation of these cells in the Alport mouse kidneys. Our results suggest that $\alpha 1 \beta 1$ integrin-positive monocytes are indeed selectively recruited to the interstitium and the rate of transendothelial migration increases over time. We used Phage display and biopanning strategies to identify the $\alpha 1 \beta 1$ integrin ligand involved in selective recruitment as collagen XIII (a membrane bound collagen). Collagen XIII mRNA and protein are induced in the vascular endothelium of Alport mice. Monoclonal antibodies raised against the binding site on collagen XIII for $\alpha 1 \beta 1$ integrin block monocyte adhesion to collagen XIII on embryonic fibroblasts, and when administered systemically to Alport mice, markedly decrease monocyte efflux into the tubulointerstitial space. Matrix accumulation and tubulointerstitial damage are also markedly reduced. Collectively, these data suggest that collagen XIII is an inducible endothelial cell ligand for $\alpha 1 \beta 1$ integrin on peripheral blood monocytes, and mediates monocyte adhesion and transmigration. Blocking collagen XIII may provide a novel therapeutic target for chronic inflammatory diseases where $\alpha 1 \beta 1$ integrin-positive interstitial monocytes (or T-cells) play a role.

\section{Materials and Methods}

\section{Mice}

All mice were in the 129 Sv genetic background. Alport mice, integrin $\alpha 1$-null mice and double knock-out (DKO) mice have all been described previously. ${ }^{4,7,11}$ All mice were used under a protocol approved by the Institutional Animal Care and Use Committee in accordance with the Guide for Care and Use of Laboratory Animals, and every effort was made to minimize pain and discomfort.

\section{Cell Culture}

Murine bone marrow was isolated by flushing the marrow cavities of the femur with Dulbecco's modified Eagle's medium (DMEM) supplemented with $2 \%$ fetal calf serum (FCS), and 1\% pen/strep. Marrow cell clusters were passed through 1-ml syringe several times to dissociate cells. Cell suspension was washed $2 \times$ in Hanks' balanced salt solution (HBSS) (Gibco BRL). Pelleted cells were resuspended in ammonium chloride solution $\left(20 \mathrm{mmol} / \mathrm{L}\right.$ Tris, and $100 \mathrm{mmol} / \mathrm{L} \mathrm{NH}_{4} \mathrm{Cl}$, $\mathrm{pH}$ 7.2) and incubated for 5 minutes to remove red blood cells. Murine primary bone marrow derived monocytes were washed in DMEM with $2 \%$ FCS, then a final wash with HBSS. Cells were cultured in DMEM supplemented (Gibco, BRL) with $2 \%$ FCS.

Endothelial cells were isolated from murine kidneys using a previously described method ${ }^{24}$ with some mod- 
ifications. Four 10-week-old DKO mice were anesthetized and perfused with ice-cold PBS. Kidneys were harvested and immediately minced on ice in HBSS, then digested in $20 \mathrm{ml}$ of $1 \mathrm{mg} / \mathrm{ml}$ collagenase A (Roche Diagnostics Corp., Indianapolis, IN) prepared in HBSS solution at $37^{\circ} \mathrm{C}$ for 45 minutes with gentle agitation. Digested material was filtered through a 70- $\mu \mathrm{m}$ nylon mesh and collected.

Cells were collected by centrifugation and washed $2 x$ in PBS. One $\mathrm{ml}$ of cell suspension was combined with $1 \times$ $10^{7}$ anti-CD31 coated metallic beads and mixed on a nutator for 30 minutes at $4{ }^{\circ} \mathrm{C}$. Rosetted cells were washed $4 \times$ in PBS with $0.1 \%$ bovine serum albumin using a metallic chamber. The metallic beads were liberated from the isolated endothelial cells with $0.5 \%$ trypsin (Gibco). Murine primary renal endothelial cells were cultured in DMEM-F12 supplemented with 50 $\mu \mathrm{g} / \mathrm{ml}$ endothelial mitogen (Biomedical Technologies Inc., Stoughton, MA), 1\% penicillin/streptomycin (Gibco, BRL), $20 \mathrm{mmol} / \mathrm{L}$ L-glutamine, $1 \mathrm{U} / \mathrm{ml}$ heparin, and $20 \%$ FCS. The cells were immunopositive for CD-31 and formed microtubules in Matrigel after 72 hours in culture.

Mouse embryonic fibroblasts were isolated from day 14 post copulation embryos. Skin was removed with forceps and treated with $0.25 \%$ trypsin/EDTA for 5 minutes at $37^{\circ} \mathrm{C}$.

\section{Antibodies}

Monoclonal antibodies were raised against the peptide sequence GEKGAEGSPGL. The peptide was conjugated to KLH and mouse monoclonal antibodies raised at the University of Nebraska monoclonal core facility. Polyclonal antibodies were raised against the custom synthesized peptide sequence (GELGAPGPGTVALAEQ) from the NC1 domain of collagen XIII and produced by Invitrogen, Inc. (Carlsbad CA). Antibodies were qualified by enzyme-linked immunosorbent assay and immunostaining of collagen XIII Chinese hamster ovary $(\mathrm{CHO})$ cells versus wild type cells (see below). All Alexa-fluorochrome conjugated secondary antibodies were purchased from Molecular Probes (Seattle, WA). Peroxidase conjugated secondary antibodies were purchased from Sigma (St. Louis, MO).

Monocyte/macrophage specific marker $\alpha$-CD11b was purchased from Cedar Lane Laboratories (Hornby, Ontario). Endothelial marker $\alpha$-CD31 was purchased from Abcam (Cambridge, UK) and anti- $\alpha 1 \beta 1$ integrin antibodies were generously provided by Biogen Corp (Cambridge, MA), and described earlier. ${ }^{25}$ Anti-CD68 antibodies were from AbD Serotec (Raleigh, NC).

\section{Anti-Collagen XIII Antibody Qualification}

The qualification of the AB2 antibody specificity was demonstrated using $\mathrm{CHO}$ cells either Mock-transfected, or transfected to a construct encoding the human collagen XIII linked to the mCherry fluorescent marker protein. Cloning of collagen XIII-mCherry chimera is based on two constructs, pRSET-B-mCherry ${ }^{26}$ and hCOLXIII/pcDNA3.1 (Hashimoto T. unpublished data). Human collagen XIII CDNA was amplified by PCR from a human brain CDNA library using primers: HindIII-COLXIII fwd: 5'-GGATAGAAGCTTTTGGCAGCGGCTGTCGC-3' . Xhol-COLXIII rev: 5'-AATACTCGAGGTACAAACACACACACAGGC-3', and then inserted following standard procedures into the HindIII and Xhol sites of pcDNA3.1(+)/hygromycin expression vector (Invitrogen). hCOLXIII/pcDNA3.1 was digested by HindIII and Xhol to form a HindIII-COLXIII-Xhol (2kb) and a HindIII-vector-Xhol (5.6 kb). HindIII-COLXIIIXhol (2kb) was further digested by Mfel to form a HindllICOLXIII(1.8kb)-Mfel and a Mfel-COLXIII(0.2kb)-Xhol. Collagen XIII with a linker to mCherry was amplified from Mfel-COLXIII(0.2kb)-Xhol using primers: XIII-Mfel fwd: 5'GTATTCCAGGACCAATTGGAGTTC-3'. XIII-mCherry rev: 5'-TCCTCGCCCTTGCTCACCATCTTGTTCCAGCAGCCTTGGACT-3'. mCherry with a linker to collagen XIII was amplified from pRSET-B-mCherry using primers: XIIImCherry fwd: 5'-AGTCCAAGGCTGCTGGAACAAGATGGTGAGCAAGGGCGAGGA-3'. mCherry-Xhol rev: 5'-TCTAGACTCGAGTTACTTGTACAGCTCGTCCAT-3'.

The two PCR products from steps 2 and 3 were used as templates for overlapping PCR with primers XIIIMfel fwd and mCherry-Xhol rev. The product is MfelCOLXIII (0.2kb)-mCherry-Xhol. The fragment from step 4 together with HindIII-COLXIII (1.8kb)-Mfel was then ligated into Hindlll-vector-Xhol (5.6 kb) using T4 ligase (Fermentas) to form a transfection plasmid COLXIIImChery/pcDNA3.1. CHO-K1 cells (ATCC) was transfected using FuGene HD (Roche) reagents. The stable transfected clones were selected by $200 \mu \mathrm{g} / \mathrm{ml}$ hygromycin.

\section{Immunohistochemistry for $\mathrm{CHO}$ Cells}

Cells grown on cytology slides (VWR, Batavia, IL) were rinsed with PBS, fixed with $-20^{\circ} \mathrm{C}$ acetone for 5 minutes and dried for 2 hours at $25^{\circ} \mathrm{C}$. Slides were rehydrated with PBS for 5 minutes, permeabilized with $0.3 \%$ Triton $X-100$ (Sigma) in PBS for 10 minutes, followed by three successive PBS washes and then incubated with Image-iT FX signal enhancer (Invitrogen, Grand Island, NY) for 30 minutes, humidified at $25^{\circ} \mathrm{C}$. The slides were rinsed with PBS and blocked with $2 \%$ FCS, $0.2 \%$ fish gelatin (Sigma) in PBS for 2 hours. The slides were incubated in blocking solution with $0.3 \mu \mathrm{g} / \mathrm{ml}$ mouse anti-collagen XIII antibody overnight, humidified at $4^{\circ} \mathrm{C}$. After three PBS washes, slides were incubated in blocking solution with a 1:1500 dilution of Alexa Fluor 488 goat $\infty$ mouse IgM (Invitrogen) for 2 hours, humidified at $25^{\circ} \mathrm{C}$. After three PBS washes, slides were cover-slipped with Vectashield mounting medium with 4,6-diamidino-2phenylindole (Vector, Burlingame, CA) and confocal images captured under a Zeiss AxioPlan 2IF MOT 
microscope interfaced with a LSM510 META confocal imaging system. Final images were assembled using Adobe Photoshop and Illustrator software (Adobe Systems, San Jose, CA).

Collagen XIII IP Western: $50 \mu \mathrm{g}$ of total cellular or glomerular lysate and $5 \mu \mathrm{g}$ of AB-2 monoclonal $\mathrm{Ab}$ were incubated overnight at $4^{\circ} \mathrm{C} .20 \mu$ of Protein $L$ Sepharose (Pierce, Rockford, III) was added to each sample and rocked for 2 hours at $4^{\circ} \mathrm{C}$. Samples were spun at 13,200 rpm at $4^{\circ} \mathrm{C}$, supernatant removed and pellet washed with $1 \mathrm{ml}$ of $1 \mathrm{~mol} / \mathrm{L} \mathrm{NaCl}$ in PBS. Pellets were spun and washed an additional five times in $1 \mathrm{ml}$ of PBS. $25 \mu \mathrm{l}$ of SDS reducing buffer was added to pellets, boiled 3 minutes and centrifuged. $20 \mu$ lof each samples was loaded on a $7.5 \%$ SDS-polyacrylamide electrophoresis gel and fractionated for 45 minutes at 200 volts. Transfer to polyvinylidene difluoride membrane (Bio Rad, Hercules, CA) was completed in 1 hour at 100 volts in $25 \mathrm{mmol} / \mathrm{L}$ Tris, $192 \mathrm{mmol} / \mathrm{L}$ glycine buffer. The membrane was blocked in $1 \%$ bovine serum albumin (BSA), PBS plus $0.1 \%$ Tween for 2 hours at room temperature. An anti-rabbit polyclonal $\mathrm{Ab}$ against Collagen XIII was used to probe the membrane at 1:20,000 in blocking buffer overnight at $4^{\circ} \mathrm{C}$ and subsequently washed three times with PBS plus $0.1 \%$ Tween for 15 minutes. The membrane was incubated with anti-rabbit IgG (Sigma) 1:50,000 in blocking buffer and washed as before. The membrane was developed using enhanced chemiluminescence solution (Pierce) and exposed to film. Controls included no lysate plus AB-2/beads and lysate plus IgM/beads.

\section{In Vivo Monocyte Transendothelial Migration Assay}

Fluorescent dextrans were prepared according to the methods described by Luby-Phelps ${ }^{27}$ with some modifications. Briefly, $1 \mathrm{mg}$ of Alexa 568 (Molecular Probes, Inc. Eugene, OR) was combined with $39 \mathrm{mg}$ of dextran (mol. wt $\sim 144,000$ ) in the presence of pyridine, dimethyl sulfoxide, and tin dilaurate (Sigma-Aldrich Co.). Labeled dextran (ADC568) was precipitated with 95\% ethanol, dialyzed in glass-distilled water and lyophilized. The dried product was then stored in $500 \mu \mathrm{g}$ aliquots at \{minus $] 20^{\circ} \mathrm{C}$ in a desiccator, protected from light.

The collagen $\alpha 3$ (IV) knockout (Alport) mice were described previously. ${ }^{4}$ Development and characterization of integrin $\alpha 1$-null and collagen $\alpha 3$ (IV)-null DKO mice was also described previously. ${ }^{6}$ Male wild type $129 S V$ and 129SV/J mice along with Alport and DKO mice were tail vein injected with $50 \mu \mathrm{g}$ of Alexa 568 labeled dextran reconstituted in $100 \mu \mathrm{l} \mathrm{HBSS}(\mathrm{pH} 7.2)$. Animals were given a single injection at weekly intervals ranging from 4 to 12 weeks (WT), 5 to 8 weeks (Alport), and 8 to 12 weeks (DKO). The high molecular weight dextrans do not cross the vascular endothelium, but are phagocytized by circulating monocytes which become labeled. Under conditions of inflammation, the labeled cells will cross the endothelium into the interstitial spaces at the inflamma- tory site. Three days post injection animals were anesthetized with Avertin $(0.55 \mathrm{mg} / \mathrm{g}$ body weight; i.p.) and perfused with ice cold PBS. Kidneys were removed, immersed in 30\% ice-cold sucrose for 3 hours, embedded in Tissue Tek optimal cutting temperature mounting medium (Sakura Finetek USA, Inc., Torrance, CA) and stored at $-80^{\circ} \mathrm{C}$.

Fresh frozen kidney sections ( $4 \mu \mathrm{m})$ were fixed in $2 \%$ paraformaldehyde. CD11b positive cells were labeled in three sections at least $100 \mu \mathrm{m}$ apart then coverslipped with mounting medium (0.1 $\mathrm{g} \mathrm{N}$-propyl-Galate, $5 \mathrm{ml}$ PBS, $5 \mathrm{ml}$ glycerol). Approximately ten pictures were taken of each section using an Olympus BH2-RFCA microscope. Images were recorded (number of red/green cells per 200× field) using a Spot RT digital camera and analyzed with Image Pro Plus software (Media Cybernetics, Inc. Silver Spring, MD).

\section{Generation of Randomly Primed Murine Kidney Endothelial Cell cDNA Library}

Endothelial cells were isolated from 7-week-old Alport kidneys as described above. Poly $\mathrm{A}^{+}$RNA was isolated and cDNA was generated with HIND III random primers and methylated dNTPs provided in the Orient Express T7 Select Phage expression system (Novagen, Inc., Madison WI). EcoRI/HIND III linkers were ligated to the cDNA, followed by digestion with HINDIII and EcoRI restriction enzymes. The digested product was filtered through a size fractionation column (Novagen, Inc., Madison WI). cDNA larger than 300bp was collected then ligated to T7 select vector arms for preparation of the phage library using T7 select phage packaging extract (Novagen, Inc., Madison WI). The number of recombinants was determined by plaque assay using bacterial strain BLT5403 (Novagen, Inc., Madison WI).

\section{Biopanning for $\alpha 1 \beta 1$ Integrin Binding Expressed Protein Sequence}

Immulon 2HB 96 well plates (Fisher Scientific) were coated with human $\alpha 1 \beta 1$ integrin purified from placenta ( $\alpha 1 \beta 1$ integrin, Chemicon Intl., Temecula, CA) at $5 \mu \mathrm{g} / \mathrm{ml}$ in coating buffer $(0.035 \mathrm{~mol} / \mathrm{L} \mathrm{NaHCO}, 0.015 \mathrm{~mol} / \mathrm{L}$ $\mathrm{Na}_{2} \mathrm{CO}_{3}$ ) overnight at $4^{\circ} \mathrm{C}$. After coating with $\alpha 1 \beta 1$ integrin, the wells were washed $3 \times$ with $1 \times$ Tris-buffered saline, blocked with $5 \%$ nonfat milk Tris-buffered saline buffer then washed $5 \times$ with distilled water. Phage preps (titer $\sim 5.9 \times 10^{8} / \mathrm{ml}$ ) were added to $\alpha 1 \beta 1$ integrin coated wells in $200 \mu \mathrm{l}$ biopanning buffer $(10 \mathrm{mmol} / \mathrm{L}$ Tris- $\mathrm{HCl}, \mathrm{pH}$ 8.0, $0.15 \mathrm{~mol} / \mathrm{L} \mathrm{NaCl}, 0.1 \%$ Tween-20, $1 \mathrm{mmol} / \mathrm{L} \mathrm{MgCl}_{2}, 1$ $\mathrm{mmol} / \mathrm{L} \mathrm{CaCl}_{2}$ ) and kept at room temperature for $45 \mathrm{~min}$ utes. Wells were washed $5 \times$ with biopanning buffer and bound phage were eluted with elution buffer $(20 \mathrm{mmol} / \mathrm{L}$ Tris, neutral pH, 1.0\% SDS) for 20 minutes. BLT5403 bacterial cells were then added to the coated wells to 
recover high affinity phage that may not have been collected in the eluate. $90 \%$ of the eluted phage were combined with $50 \mathrm{ml}$ bacterial cell culture at $\mathrm{OD}_{600}=0.5$ and amplified for 3 hours at $37^{\circ} \mathrm{C}$ with shaking. The remaining $10 \%$ was used to determine the number of phage recovered from each round of biopanning. Amplified phage from each round of biopanning was titered by plaque assay. The biopanning procedure was repeated $3 \times$ with $1 \times 10^{8}$ phage $/ \alpha 1 \beta 1$ integrin-coated well for a total of four rounds of biopanning.

\section{PCR and Sequencing of $\alpha 1 \beta 1$ Integrin-Selected Plaques}

Amplified phage collected after the fourth round of biopanning were diluted and individual plaques collected for sequence analysis. One $\mathrm{ml}$ phage extraction buffer (20 $\mathrm{mmol} / \mathrm{L} \mathrm{Tris-HCl}, \mathrm{pH} 8.0,100 \mathrm{mmol} / \mathrm{L} \mathrm{NaCl}, 6 \mathrm{mmol} / \mathrm{L}$ $\mathrm{MgSO}_{4}$ ) was added to each plug and stored at $4^{\circ} \mathrm{C}$. Plaques were dispersed in $100 \mu \mathrm{l}$ of $10 \mathrm{mmol} / \mathrm{L}$ EDTA, pH 8.0, vortexed, and kept at $65^{\circ} \mathrm{C}$ for 10 minutes. Samples were cooled to room temp and centrifuged at $14000 \times g$ for 3 minutes. The recovered DNA was amplified with T7-select up (5'-GGAGCTGTCGTATTCCAGTC-3') and down -(5'-AACCCCTCAAGACCCGTTTA-3') primers using the following cycling parameters: heat the reaction to $94^{\circ} \mathrm{C}$ with DNA polymerase for 2 minutes, then 35 cycles $\left(94^{\circ} \mathrm{C}\right.$ for 50 seconds; $50^{\circ} \mathrm{C}$ for 1 minute; $72^{\circ} \mathrm{C}$ for 1 minute) followed by a final extension at $72^{\circ} \mathrm{C}$ for 6 minutes. Amplified cDNA inserts were then sequenced. Sequences were screened for short nearly exact matches within the $\mathrm{NCBI}$ database.

\section{Northern Blot Analysis}

Northern blots analysis was performed as described previously. ${ }^{9}$ Ten micrograms of total glomerular RNA was fractionated on $1 \%$ agarose formaldehyde gels and transferred to nylon membranes. Probes were either a gel purified PCR fragment of the collagen XIII transcript amplified using primers that recognize the NC4 domain of type XIII Collagen, or the DECAprime template for mouse $\beta$-actin (Ambion, Inc., Austin TX). Probes were labeled with ${ }^{32} \mathrm{P}$-dCTP using either random primers or the DECA method provided by the manufacturer. Hybridizations were carried out overnight at $50^{\circ} \mathrm{C}$ using ULTRAhyb hybridization buffer (Ambion), and the membranes washed according to the manufacturer's instructions. Membranes were exposed to X-ray film overnight.

\section{Quantitative Reverse Transcription-PCR}

Endothelial cells were isolated from total kidney using metallic beads conjugated to anti-CD31 antibodies. Total RNA was isolated using Trizol reagent (Invitrogen) with glycogen (Invitrogen) as a carrier per manufacturer protocol; $1.5 \mu \mathrm{g}$ of total RNA was used as template for a reverse transcriptase reaction. The reverse transcription reaction was performed using Super Script III (Invitrogen) as suggested by manufacturer. iQ SYBR Green Supermix (Bio Rad), primers that recognize the NC4 domain of type XIII Collagen and primers specific to murine glyceraldehyde-3-phosphate dehydrogenase were used in the quantitative PCR reactions. The reactions were carried out in triplicate using a 1:10 dilution of the cDNA generated. Standard curves for use in the quantification of relative RNA expression were generated for both type XIII collagen and the glyceraldehyde-3-phosphate dehydrogenase endogenous control.

\section{Adhesion Assay}

Bone marrow was collected from the femurs of 7-weekold wild-type $129 \mathrm{~Sv}$ mice and integrin $\alpha 1$-null mice as described above. Cells were suspended in DMEM/ Ham's F-12 containing $25 \mu \mathrm{mol} / \mathrm{L}$ cell tracker dye, incubated at $37^{\circ} \mathrm{C}$ for 45 minutes and centrifuged. The cells were washed two times with PBS, were resuspended in DMEM/F12 medium. The stained cells were plated at 7000 cells/ well onto primary embryonic fibroblast monolayers in 48-well dishes and incubated at $37^{\circ} \mathrm{C}$ for 3 hours. After removing the media, the attached cells were washed in PBS and the optical density was measured at $567 \mathrm{~nm}$ using microplate reader (EL 800, Bio-Tek Instruments, Inc., Winoski, VA). The optical density was compared with respect to wild type and the results were expressed as arbitrary units. Three independent experiments were performed in triplicate, and the results statistically analyzed.

\section{Transwell Migration Assay}

\section{Bone Marrow Isolation}

Bone marrow was isolated from four 5- to 8-weekold, wild-type mice. Femur cavities were flushed with basal DMEM/Ham's F-12 media. Upon dissociation of clusters, cells were pelleted and washed twice with D-PBS, resuspended in ammonium chloride solution to remove RBC's, washed two more times with D-PBS and resuspended in seven milliliters of D-PBS containing $5 \%$ FCS.

\section{VLA-1 Panning}

Five $\mu \mathrm{g} / \mathrm{ml}$ anti- $\alpha 1 \beta 1$ Integrin antibody (Biogen) was adhered to polystyrene bacteriological petri dishes as described. Antibody was incubated overnight at $4^{\circ}$, followed by 2 hours at room temperature, aspirated, washed four times with D-PBS and one time with D-PBS, 1\% FCS. 3.5 milliliters of bone marrow suspension was then applied to each of two antibody-coated dishes and incubated for 1 hour at $4^{\circ}$, swirled and placed at $4^{\circ}$ for 
one additional hour. The suspension was removed, the dishes were gently washed four times with D-PBS, $1 \%$ FCS, followed by two additional washes with gentle swirling. Bound cells were collected by flushing three times with D-PBS, 1\% FCS, combined and spun at $1200 \mathrm{rpm}$ for 10 minutes. The pellet was resuspended in $10 \mathrm{ml}$ of DMEM/F-12, 0.1\% fraction V BSA (Roche) and rocked at $4^{\circ}$ for 15 minutes. This was repeated twice more to liberate residual bound VLA1 antibody captured during the panning process. The cells were resuspended in $6 \mathrm{ml}$ of DMEM/F-12, 0.1\% BSA.

\section{Transwell Setup}

A 3- $\mu \mathrm{m}$ polyethylene terephthalate membrane 6-well cell culture insert (BD Biosciences, San Jose, CA) was coated with $4 \mu \mathrm{g} / \mathrm{cm}^{2}$ human fibronectin (BD Biosciences) as recommended by manufacturer. Irradiated murine embryonic fibroblasts were plated for confluency in DMEM/F-12, 5\% FCS and allowed to attach overnight. The fibroblast monolayer was carefully rinsed two times with $\mathrm{Ca}^{2+}, \mathrm{Mg}^{2+}$ free D-PBS and incubated with 0.5 milliliters of DMEM/F-12, $0.1 \%$ BSA containing $10 \mu \mathrm{g} / \mathrm{ml}$ of collagen XIII neutralizing antibody (AB-2), or IgM control antibody; $0.5 \mathrm{ml}$ DMEM/F-12, 0.1\% BSA containing 4 to $5 \times 10^{5}$ VLA1-panned bone marrow cells were loaded onto the fibroblast-containing inserts. The inserts were carefully placed into a 6-well plate containing $1.5 \mathrm{ml}$ DMEM/F-12, 5\% FCS and incubated overnight (14 hours) at $37^{\circ}, 5 \% \mathrm{CO}_{2}$. After overnight incubation, cells were collected from the upper (insert) and the lower (6-well plate).

\section{Flow Analysis}

Collected pellets were resuspended and blocked in DMEM/F-12, $1 \%$ FCS. Cells were reacted with anti- $\alpha 1 \beta 1$ integrin antibody conjugated with DyLight Dye 649 (Pierce) and R-phycoerythrin-conjugated rat anti-mouse CD11b monoclonal antibody (BD Biosciences) for 30 minutes at room temperature. Cells were washed three times with DMEM/F-12, 1\% FCS, and fixed in 1\% formalin. Flow cytometry data were acquired and analyzed using a fluorescence-activated cell sorting Aria and Cell Quest Pro Software (BD Biosciences).

In Vivo studies for effect of AB2 injections in amelioration of Alport interstitial fibrosis: Alport mice (five animals per group) were injected via the tail vein two times weekly with 25 micrograms of either the collagen XIII-specific AB2 monoclonal antibody or a nonreactive isotype matched control antibody (IgM from Zymed laborites, now Invitrogen) from 4 to 7 weeks of age. Proteinuria was measured as described previously (Meehan et al, 2009). Tissue was harvested and embedded in paraffin and stained with H\&E. Fibrosis scoring was done by estimating the total area of fibrosis (hypercellularity with loss of tubular architecture) per total area of renal cortex with
5 to $15 \%$ being scored 1,15 to $25 \%$ being scored a 2 , 25 to $35 \%$ being scored a 3 , and $>35 \%$ being scored a 4 . The \% glomerular sclerosis was scored by simply counting the total number of glomeruli per slide and expressing the number of sclerotic glomeruli as a \% fraction of the total. Three slides (cut at $100 \mu \mathrm{mol} / \mathrm{L}$ intervals within a given kidney sample) were examined from five individual mice per group.

\section{Statistical Analysis}

Data are expressed as mean $\pm S D$. Differences between means were tested for significance using Student's $t$-test. Where mentioned, Bonferonni correction was applied. Differences were considered significant at the level of $P<0.01$.

\section{Results}

$\alpha 1 \beta 1$ Integrin Expression Influences the Rate at Which Monocytes Accumulate in the Interstitial Space of Alport Mice

We have previously noted that interstitial monocytes in Alport kidneys are mostly immunopositive for $\alpha 1 \beta 1$ integrin. ${ }^{10}$ These data, however, do not directly implicate a role for $\alpha 1 \beta 1$ integrin on peripheral blood monocytes transmigration into the renal interstitium. To address this, we developed an in vivo monocyte transmigration assay. Dextrans were labeled with Alexa 568 fluorochrome and injected in to the tail vein of either Alport or integrin $\alpha 1$-null Alport (DKO) mice at varying ages representing different stages in the progression of fibrosis in the two mouse models. The high molecular weight dextrans do not cross the vascular endothelium, but are phagocytized by circulating monocytes which become labeled. Under conditions of inflammation, the labeled cells will cross the endothelium into the interstitial spaces at the inflammatory site. Three days following the injection of Alexa-conjugated dextrans, the kidneys were harvested. Cryosections were prepared and either analyzed directly by immunofluorescence, or counterstained with a second antibody and then analyzed. Figure 1 shows representative fields of newly effluxed monocytes for wild-type mice (Figure 1A), 6-week-old Alport mice (Figure 1C), or 8-week-old Alport mice (Figure $1 \mathrm{E}$ ). The Alexa-labeled cells are identified as monocytes by counterstaining with either anti-CD68 (Figure 1D) or anti-CD11b (Figure 1, B and F) antibodies.

Figure 2 shows the kinetics of monocyte accumulation in the two mouse models as a function of disease progression. The number of Alexa-labeled (newly effluxed) monocytes 3 days following tail vein injection was plotted. Each bar represents fields at $\times 200$ magnification from at least 10 independent fields of cryosections from each of three individual animals. When the data are plotted linearly, the slope of the resulting line reflects the differential 

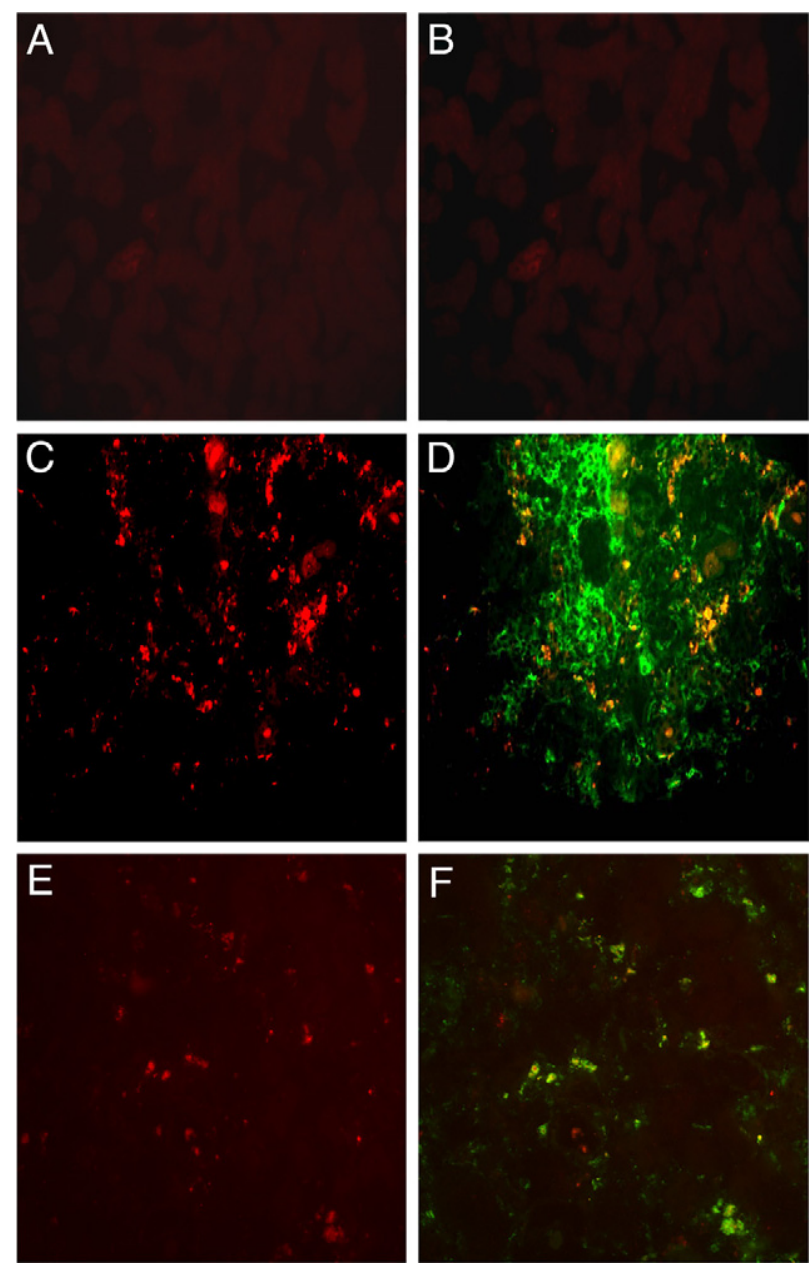

Figure 1. Monocytes are effluxing into the renal cortical interstitium of Alport mice. Wild-type mice (A and B), 6-week-old Alport mice (C and D), or 8-week-old Alport mice (E and $\mathbf{F}$ ) were injected with Alexa-conjugated dextrans three days before the kidneys were harvested. Newly effluxed monocytes are labeled red $(\mathbf{A}, \mathbf{C}$, and $\mathbf{E})$. Serial sections were counterstained with either anti-CD68 antibodies (D) or anti-CD11b antibodies (F) to identify dextran-labeled interstitial cells as monocytes. Fields are representative of three independent experiments.

rate of monocyte efflux for the two mouse models. The slope of the line for Alport mice is significantly higher than the slope for DKO mice, indicating that the rate of monocyte efflux is decreased, even after the delayed onset, in DKO mice relative to Alport mice.

\section{Collagen XIII Is Induced in Vascular Endothelial Cells of Alport Kidneys, and Binds to $\alpha 1 \beta 1$ Integrin}

In an attempt to identify the endothelial cell ligand for $\alpha 1 \beta 1$ integrin, we used a biopanning approach. First, a cDNA expression library was constructed using RNA from vascular endothelial cells freshly isolated from Alport kidneys. The cDNA is expressed by the phage used to package the library, and the expressed peptides presented at the surface of the phage capsids.

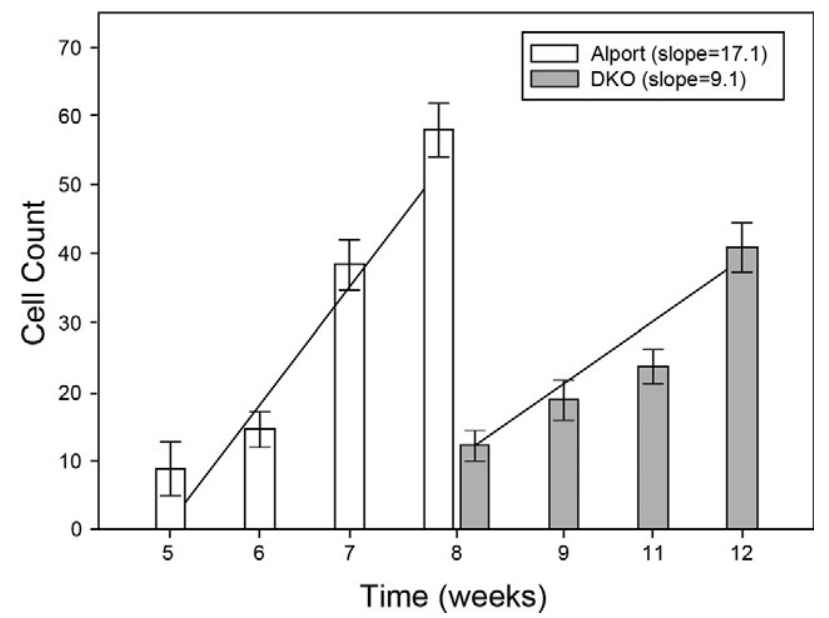

Figure 2. The rate of monocyte efflux is markedly reduced in integrin $\alpha 1$-null Alport (DKO) mice relative to Alport mice. Animals were injected with Alexa-conjugated dextrans and harvested three days later at the indicated ages. The number of red (Alexa 568-positive)/green (CD11bpositive) dual-positive cells were quantified blinded with image pro plus software. Ten fields per section were quantified for three sections in triplicate experiments. Numbers represent the mean and standard deviations. The slopes of the best-fit curves are provided, showing a much greater slope for Alport mice compared to integrin $\alpha 1$-null Alport mice, consistent with a much slower rate of $\alpha 1 \beta 1$ integrin-positive monocyte efflux in the latter.

Plates were coated with purified human placental $\alpha 1 \beta 1$ integrin (Chemicon, Temecula, CA), and the interacting peptides expressed by the phage library were captured and purified by repeated rounds of biopanning and amplification of bound phage. A single peptide was identified in overlapping peptide sequences using this method, which corresponded to a portion of the collagenous domain of collagen XIII, a membrane bound collagen. The shared sequence included amino acids GAEGSPGL, which presumably represents the minimum sequence of collagen XIII capable of specifically binding to $\alpha 1 \beta 1$ integrin. This is the human, rather than the mouse (GAAGSPGL) sequence. The frequency of positive clones was much lower than expected, suggesting that the positive clone was the result of the random priming method rather that a product of the RNA starting material.

Integrin $\alpha 1 \beta 1$ is a collagen binding integrin, and collagen XIII has been shown to bind to $\alpha 1 \beta 1$ integrin in earlier studies ${ }^{28}$ providing confidence that our findings were functionally relevant.

If collagen XIII is the ligand for $\alpha 1 \beta 1$ integrin, it should be induced on the vascular endothelium of Alport mice. To determine whether this is the case, we isolated endothelial cells from 7-week-old wild type and Alport mouse kidneys using anti-CD31 antibodies conjugated to metallic beads. RNA was extracted from the freshly isolated cells, each sample representing pools from four mice. The RNA analyzed for collagen XIII transcripts by Northern blot. The results in Figure 3 illustrate that collagen XIII mRNA is abundant in endothelial cells from Alport and nearly undetectable in endothelial cells from wild type mice. The membranes were stripped and re-probed for $\beta$-actin (a housekeeping gene) transcripts as a loading control. This exper- 


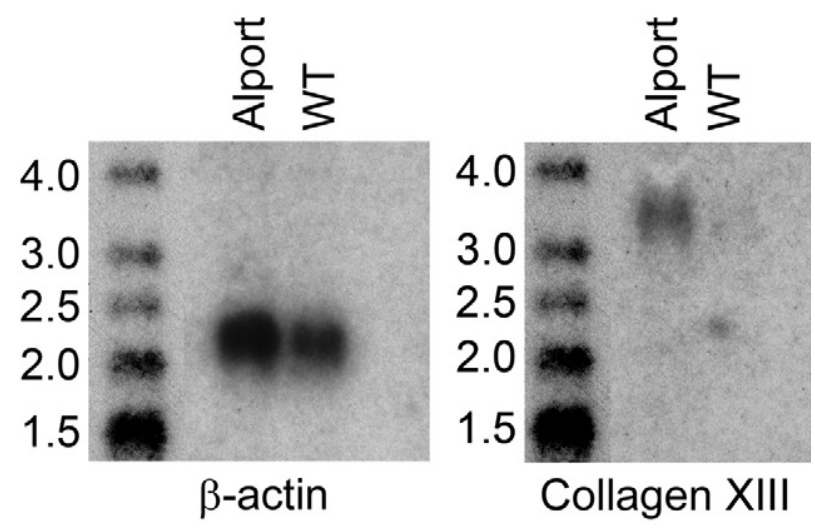

Figure 3. Collagen XIII mRNA is induced in renal vascular endothelial cells from Alport mice relative to wild-type littermates. Renal vascular endothelial cells were isolated from the kidneys of 7-week-old wild-type and Alport mice using antibody-coated metallic beads (see Materials and Methods), and the RNA was extracted and analyzed by Northern blot for expression of collagen XIII. The blot was stripped and reprobed with a $\beta$-actin cDNA to control for loading. The blot shown is representative of four independent experiments. Molecular weight markers are in kilobases.

iment was repeated several times using real time reverse transpcription-PCR (the number of mice required for Northern blots was prohibitive) with similar results (70-fold induction, on average).

\section{$\alpha 1 \beta 1$ Integrin-Positive Monocytes Bind to Collagen XIII}

The shared peptide sequence of phage purified by biopanning the endothelial cell phage display library (GAEGSPGL) was included in the synthesis of a larger peptide (see Materials and Methods), which was conjugated to KLH and used as immunogen for the generation of monoclonal antibodies. Since this peptide comprises a putative binding site on collagen XIII for $\alpha 1 \beta 1$ integrin, it was expected that these monoclonals would block binding of $\alpha 1 \beta 1$ integrin-positive monocytes to collagen XIII. The peptide identified in phage display is from a collagenous domain (the COL2 domain, Figure 4A) of the molecule. Antibodies against collagenous domains are notoriously difficult to make, and often require the preparation of triple-helical collagen. Since our peptide, when presented by the phage, bound to $\alpha 1 \beta 1$ integrin in monomeric form, we presumed the monomeric peptide might comprise a workable immunogen for the production of neutralizing monoclonal antibodies. The antibodies were affinity purified before use. Several hybridomas were selected based on enzyme-linked immunosorbent assay data, and a single derivation (Ab2) was chosen for further studies. The specificity of the antibody was determined using $\mathrm{CHO}$ cells transfected with a construct encoding a chimeric molecule comprised of human collagen XIII and the mCherry fluorescent protein. Mock transfected cells were used as a control. As shown in Figure 4B, the Ab2 collagen XIII-specific monoclonal antibody clearly recognizes the transfected cells and colocalizes with mCherry (as expected since it's a chimeric molecule). Mock transfected cells were negative for Ab2 staining. The polyclonal antibody preparation (Figure 4, panel A) gave similar results (data not shown). To further verify the antibody specificity, immunoprecipitations were carried out using Ab2 (or IgM control) on extracts prepared from isolated glomeruli (which do not express collagen XIII), Alport kidney endothelial cells, or primary murine fibroblasts cultures, and the immunoprecipitates probed with the rabbit polyclonal antibodies prepared against the NC1 domain (shown in panel I). The results in Figure $4 \mathrm{C}$ show a specific band of the appropriate molecular weight is detected in both endothelial cell extracts (lane 2) and fibroblast extracts (lane 3), but notably absent from glomerular extracts (lane 1). The control (lane 4) is fibroblast extracts immunoprecipitated with a nonreactive IgM, which is also negative.

Since the peptide used to create Ab2 was identified using phage display to probe $\alpha 1 \beta 1$ integrin coated plates, we would expect this antibody to block binding of collagen XIII to $\alpha 1 \beta 1$ integrin. A cell adhesion assay was devised using murine embryonic fibroblast monolayers as collagen XIII presenting cells. Fibroblasts were chosen, since they had previously been shown to constitutively express collagen XIII, ${ }^{29,30}$ avoiding the complication of having to induce collagen XIII on vascular endothelial cells. In addition, endothelial cells express a number of cell adhesion molecules that could confound interpretation of the results. Monocytes were obtained from the bone marrow of 129 Sv mice or $\alpha 1$ integrin knockout mice (also on the 129 Sv background) and used directly in cell adhesion experiments. Cells were labeled with cell tracker dye (Molecular Probes, Eugene, $\mathrm{OR}$ ), and layered onto confluent embryonic fibroblast monolayers in the presence or absence of the indicated antibodies (Figure 4D). After several washes, the total bound fluorescence was quantified. To examine the percent adhesion for wild type bone marrow, bound cells were stained with methylene blue and counted. Around five percentage of cells were adherent, which correlated well with data generated by fluorescenceactivated cell sorting (data not shown). We used anticollagen XIII antibody mAb2, a neutralizing antibody for $\alpha 1 \beta 1$ integrin ( $\alpha 1 \mathrm{Ab}$ ) as a positive control, and an isotype matched (IgM) nonreactive antibody (control $\mathrm{Ab}$ ) as a negative control. Bone marrow cells from integrin $\alpha 1$ null cells were used as an additional control to demonstrate the degree of adhesion of monocytes lacking $\alpha 1 \beta 1$ integrin. The results in Figure $4 \mathrm{D}$ represent four independent experiments performed in triplicate. The monoclonal antibody against collagen XIII blocked cell adhesion by approximately $80 \%$. Other mAbs against our peptide immunogen gave similar results (data not shown). The neutralizing monoclonal antibody known to block $\alpha 1 \beta 1$ integrin binding to collagen ligands ${ }^{25,31}$ also reduced binding of monocytes to the embryonic fibroblasts by approximately $80 \%$. Integrin $\alpha 1$-null cells bound similarly to wild type cells blocked with either Ab2 or $\alpha 1 \beta 1$ integrin neutralizing antibodies. Combined, these data strongly suggest 
that the $\alpha 1 \beta 1$ integrin-positive monocytes are binding to type XIII collagen on the embryonic fibroblasts, and that the monoclonals engineered against the putative binding site for $\alpha 1 \beta 1$ integrin on collagen XIII block the interaction

A

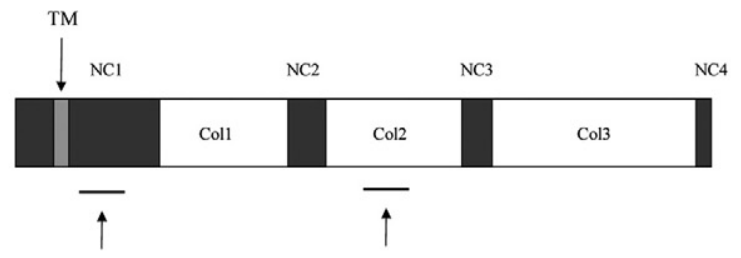

Polyclonal ab

Monoclonal ab

$\mathrm{B}$
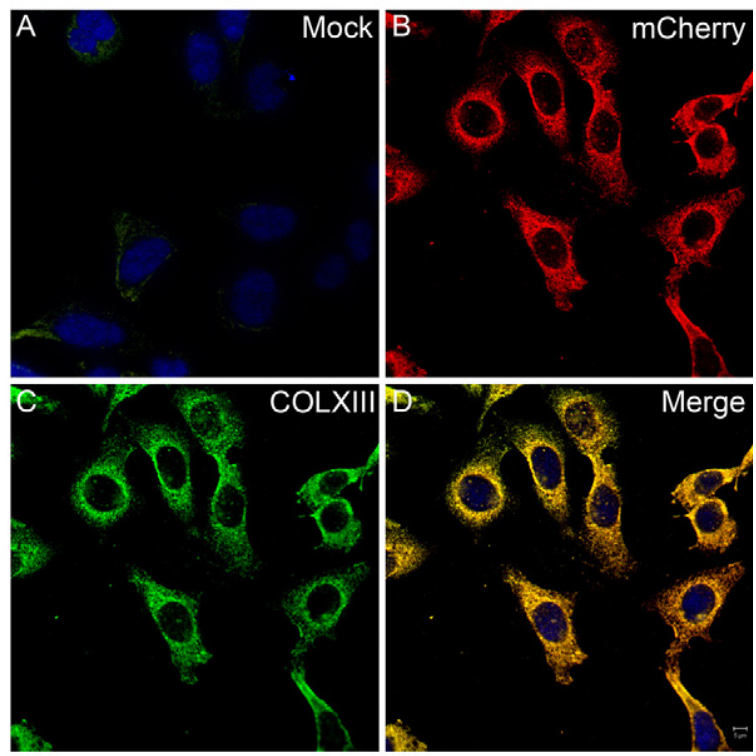

C

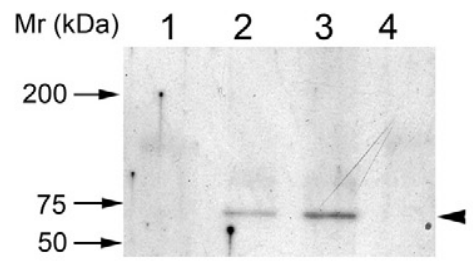

D

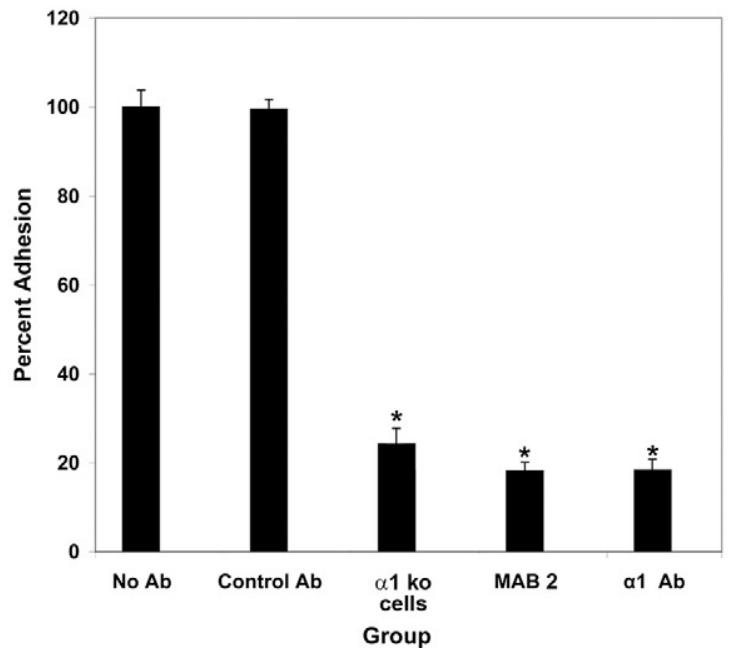

Blocking Antibodies against Collagen XIII Selectively Bind the Renal Vascular Endothelium in Alport Mice and Inhibit Recruitment of Monocytes to the Tubulointerstitium

To assess whether the collagen XIII monoclonal antibodies would bind to the endothelium in Alport kidneys under the stress of normal blood flow, antibodies were conjugated to Alexa 568 fluorochrome (Molecular Probes), and injected into the tail veins of DKO mice. The $\alpha 1$ integrinnull background was used to eliminate competition for binding with endogenous $\alpha 1 \beta 1$ integrin. Figure 5, A-F shows that the antibodies bound to the vascular endothelium of DKO mice, but not to that of age and strain matched controls. Injection of fluorescence-tagged isotype-matched control antibodies showed no binding (data not shown). Interestingly, only a fraction of the vascular endothelium bound the antibody, suggesting that collagen XIII is induced in response to changes in the immediate microenvironment. Dual immunofluorescence analysis was performed to determine whether interstitial monocytes were more abundant in areas where capillary endothelium is positive for collagen XIII, as would be expected if monocyte binding to collagen XIII is a prerequisite for transmigration. Figure 5, G-I shows that monocytes (in green) are clearly abundant in areas where capillaries express collagen XIII (in red).

These data suggest that the blocking antibodies might block transmigration of integrin $\alpha 1 \beta 1$-positive peripheral blood monocytes into the tubulointerstitial space of Alport mice. To test this, Alport mice were injected with $25 \mu \mathrm{g}$ of either the anti-collagen XIII monoclonal antibodies or nonreactive IgM control antibodies twice weekly from 4 to 7 weeks of age. At 6 weeks and 4 days, the animals were injected intravenously with Alexa-conjugated dextrans to allow direct monitoring of monocyte efflux into the tubulointerstitial spaces. Figure 6 illustrates typical fields of transmigrated monocytes over the 3-day monitoring period in Alport mice (Figure 6A) and Alport mice treated with the monoclonal antibodies (Figure 6C). Comparing

Figure 4. Production and qualification of a mouse monoclonal antibody for the $\alpha 1 \beta 1$ integrin-binding site on collagen XIII. A: Cartoon of the structura components of trans-membrane collagen XIII, showing the location of the peptide immunogen used to raise monoclonal antibodies (based on sequence derived from phage display data), and polyclonal antibodies. B: $\mathrm{CHO}$ cells were either mock transfected $(\mathbf{A})$ or transfected with a construct encoding a collagen $\mathrm{XIII} / \mathrm{mCherry}$ chimeric protein $(\mathbf{B}, \mathbf{C}, \mathbf{D})$. The cells were immunostained with Ab2 anti-collagen XIII mAb (A and C). mCherry (B) co-localizes with collagen XIII (D), demonstrating antibody specificity. C: Extracts from glomeruli (lane 1), Alport kidney endothelial cells (lane 2), and embryonic fibroblasts (lanes 3 and 4) were immunoprecipitated with Ab2 anti-collagen XIII antibodies (lanes 1-3) or IgM antibodies (lane 4). The immunoprecipitates were run on western blots and probed with rabbit polyclonal anti-collagen XIII antibodies. The arrowhead denotes a single band at the appropriate molecular weight for collagen XIII monomer. D: Monolayers of embryonic fibroblasts were used in cell adhesion experiments. Bone marrow-derived monocytes were applied to the monolayers in the presence or absence of either $\alpha 1 \beta 1$ integrin-neutralizing antibodies ( $\alpha 1$ $\mathrm{Ab}$ ), or monoclonal antibodies reactive to the peptide identified by biopanning as the binding site on collagen XIII for $\alpha 1 \beta 1$ integrin (MAB2). Bone marrow-derived monocytes from integrin $\alpha 1$ knockout mice were used as a control. The control antibody was an isotype matched (IgM) nonreactive monoclonal. Four independent experiments were performed in triplicate and analyzed statistically. There was significant differences in binding (* $P>0.05)$. 

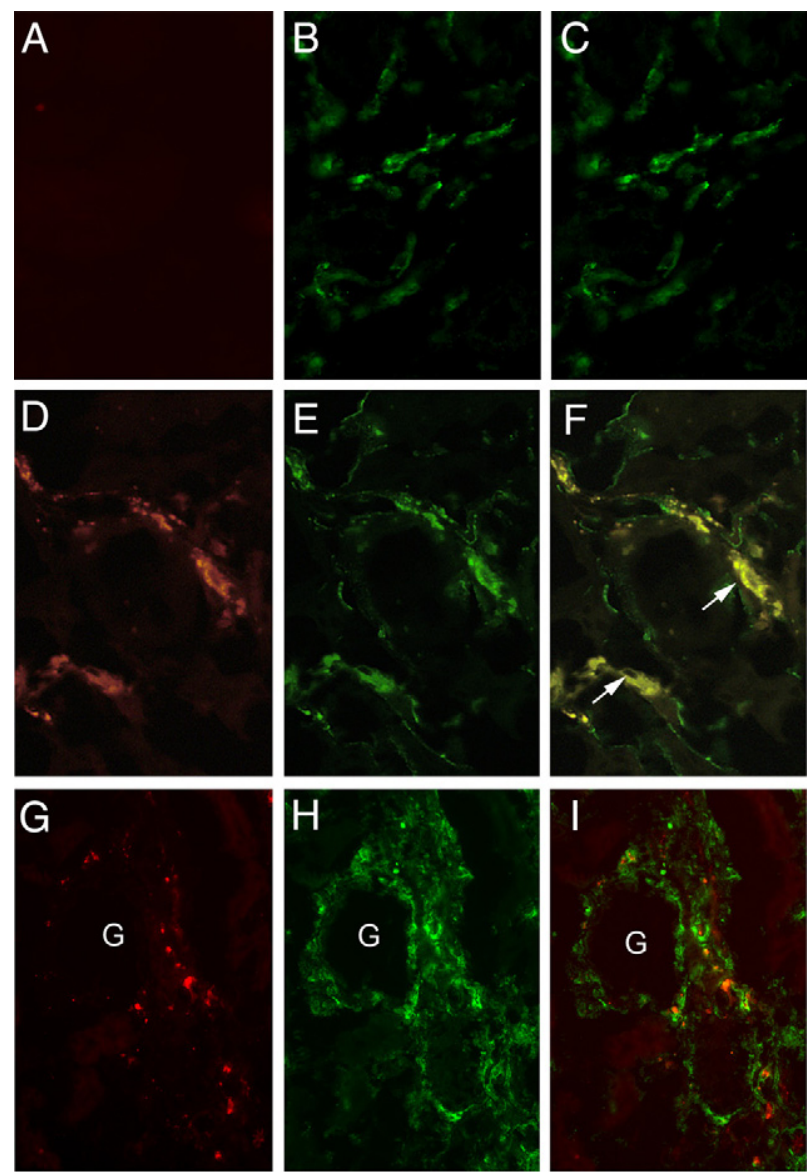

Figure 5. Monoclonal antibodies against the binding site on collagen XIII for $\alpha 1 \beta 1$ integrin bind to a fraction of the vascular endothelium in 12 -week-old integrin $\alpha 1$-null Alport (DKO) kidneys, but not wild-type littermates. Ab2 anti-collagen XIII-neutralizing monoclonal antibody was labeled with Alexa 568 and injected into the tail veins of wild-type (A-C) or DKO (D-I) mice Two hours later, the kidneys were harvested, and cryosections were counterstained with either FITC-conjugated anti-CD31 (PECAM) antibodies (B and E) or anti-CD11b antibodies (H). Alexa 568 immunostaining was not observed in wild-type kidney cryosections (A), but was abundant in DKO kidney cryosections (D and $\mathbf{G}$ ). The vascular endothelium is immunopositive for CD31 in both wild-type (B) and DKO (E) mice. F: Some, but not all, of the vascular endothelium in the DKO kidneys show binding of anti-collagen XIII antibodies. Arrows in $\mathbf{F}$ denote cross sections of blood vessels where the lumen is clearly visible. Importantly, all of the Alexa 568 (Ab2) immunostaining localizes to the vascular endothelium. G-I: Monocytes (H, CD11b labeled green) migrate into areas where collagen XIII-positive capillaries (G, red) are abundant (dual staining in $\mathbf{I}$; and $\mathrm{G}$ denotes a glomerulus, which are always negative for collagen XIII). Fields are representative of those observed for three independent mice.

Figure 6A (untreated) with Figure 6C (treated) clearly illustrates a marked reduction in the monocyte efflux when Alport mice are given the collagen XIII blocking antibody. This translates to a marked decrease in the total accumulation of interstitial monocytes, as indicated by anti-CD11b immunostaining (Figure 6, compare panels $B$ and D). This overall reduction in interstitial monocyte accumulation is associated with a similar reduction in myofibroblasts (anti-smooth muscle actin immunostaining; Figure $7 \mathrm{~A}, \mathrm{C}$, and E), as well as fibronectin accumulation (Figure $7, \mathrm{~B}, \mathrm{D}$, and F), illustrating that administration of collagen XIII blocking antibodies results in attenuated progression of interstitial fibrosis in the Alport mouse model. To gain a more quantitative appreci-

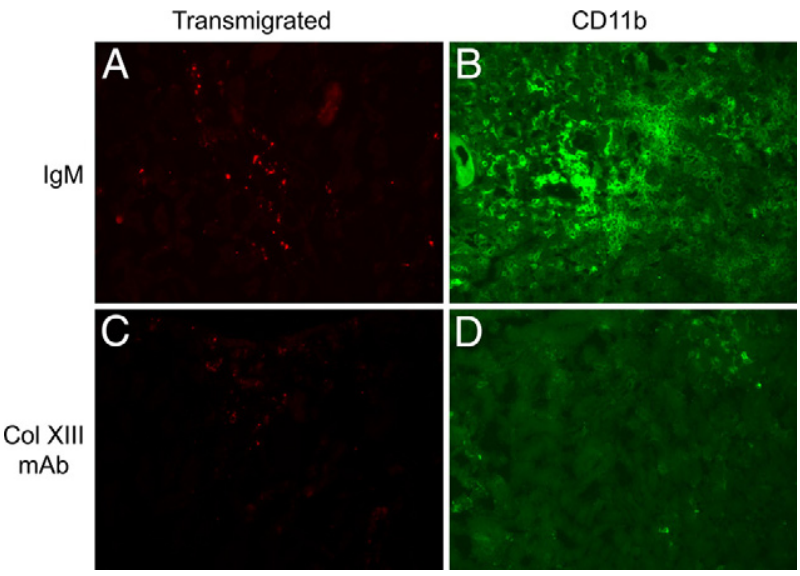

Figure 6. Treatment of Alport mice with Ab2 markedly attenuates the efflux of monocytes into the interstitium of Alport kidneys. Alport mice were given bi-weekly intravenous injections of $25 \mu \mathrm{g}$ Ab2 beginning at four weeks of age. Control mice were given the same regimen using isotype matched nonreactive antibodies (IgM). Three days before sacrifice, mice were injected with Alexa 568-conjugated dextrans. At seven weeks of age, kidneys were harvested and cryosections either visualized directly for newly effluxed monocytes (A and $\mathbf{C}$ ) or immunostained for total monocyte accumulation using anti-CD11b antibodies (B and $\mathbf{D})$. $\mathbf{A}$ and $\mathbf{B}$ show untreated Alport mice. $\mathbf{C}$ and $\mathbf{D}$ show Alport mice given the Ab2 injections. The fields shown are representative of 10 independent animals.

ation of this, five Alport mice per group were either treated with Ab2 or IgM (control) from 4 to 7 weeks of age as above, and three kidney sections per mouse (100 $\mu \mathrm{mol} / \mathrm{L}$ apart)were scored for interstitial fibrosis as described in the Materials and Methods, and the \% of sclerotic glomeruli were counted. The results in Figure 7 (bottom panels) shows that while fibrosis was markedly attenuated in the Ab2 treated mice relative to mice given IgM, the number of sclerotic glomeruli was relatively unchanged. Consistent with this, proteinuria was not affected by Ab2 treatment (data not shown).

\section{Blocking Antibodies Impede Collagen XIII-Dependent Transmigration of VLA1-Positive Bone Marrow-Derived Monocytes in Transwell Assays}

The complexity of the in vivo system can result in misinterpretation of results such as the ones presented in Figures 6 and 7 . If reduced VLA1-positive monocyte recruitment was indeed directly caused by blocking of collagen XIII binding on vascular endothelium, it should be possible to verify this using an in vitro transwell monocyte migration assay. We devised such an assay by coating membranes first with fibronectin, and then plating a confluent layer of irradiated (to arrest cell division) embryonic fibroblasts onto the fibronectin. We again used bone marrow-derived cells, which were first subjected to biopanning using anti-VLA1 antibodies to enrich for VLA1-positive monocytes. One round of biopanning increased the concentration of VLA1-positive monocytes from 6 to $8 \%$ to 40 to $50 \%$ of the total cell population. Fibroblast monolayers were preincubated with neutralizing antibodies against collagen XIII or with an equal amount of isotype matched nonreactive control antibod- 

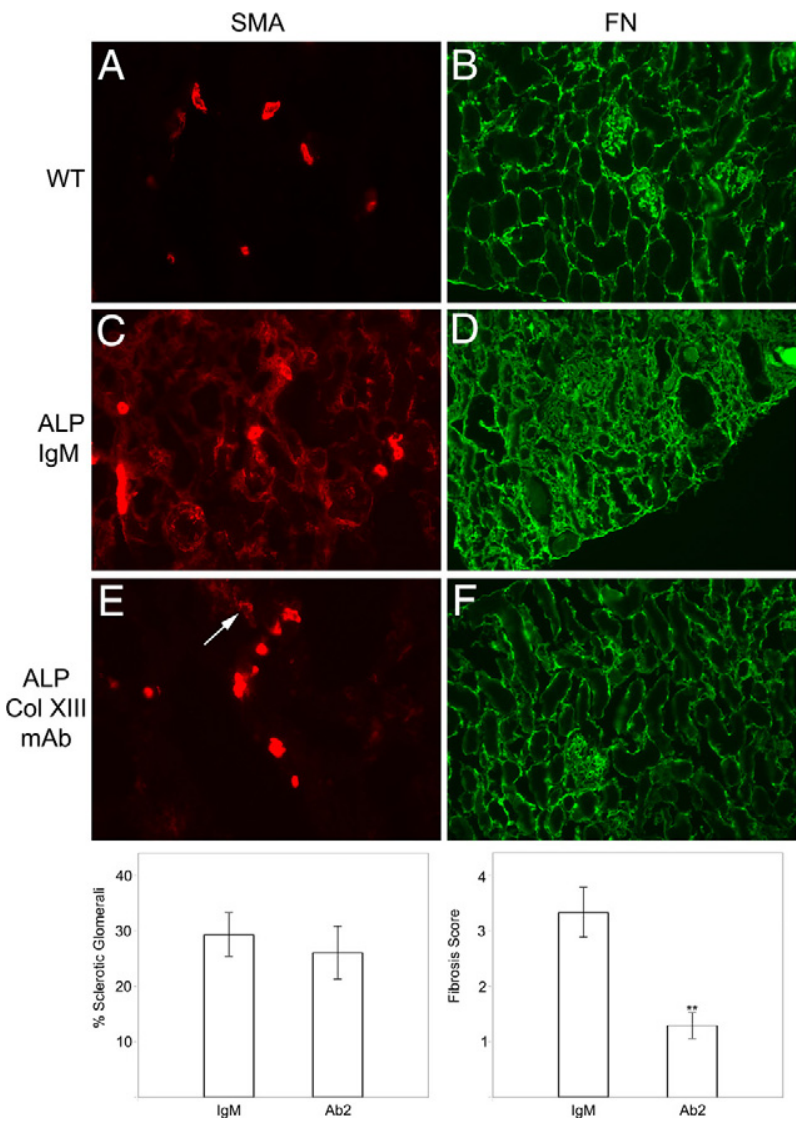

Figure 7. Treatment of Alport mice with Ab2 reduces myofibroblasts and fibrosis in the interstitium of Alport kidneys. Cryosections either control mice (A and $\mathbf{B}$ ), IgM-treated Alport mice $(\mathbf{C}$ and $\mathbf{D}$ ), or Alport mice treated with $\mathrm{Ab} 2$ (E and $\mathbf{F})$ or nonreactive isotype matched control antibody (IgM; $\mathbf{C}$ and D) were immunostained with antibodies against either smooth muscle actin (SMA, A, C, and $\mathbf{E}$ ) or fibronectin (FN, B, D, and $\mathbf{F}$ ). Both myofibroblast accumulation (SMA immunostaining) and fibrosis (as determined by fibronectin immunostaining) are markedly attenuated in renal cortex of Ab2treated mice relative to the IgM-treated mice. Arrow in $\mathbf{E}$ denotes small focus of accumulating myofibroblasts in kidney cryosection from the treated animals. The fields shown are representative of 10 independent animals. Bar graphs at bottom represent semiquantitative assessment of the influence of Ab2 treatment in Alport mice from 4 to 7 seeks of age on glomerular sclerosis (left panel) and interstitial fibrosis (right panel). Bars represent statistically analyzed stat comprising three fields for five mice in each group (IgM versus Ab2).

ies. The monocytes were then layered onto the top of the fibroblast monolayer and allowed to migrate for 14 hours using fetal calf serum in the lower chamber as the chemoattractant. Migrated cells from the bottom chamber and nonmigrated cells from the top chamber were analyzed by dual fluorescence fluorescence-activated cell sorting analysis using phycoerythrin-conjugated anti CD11b antibodies (monocyte marker) and DyLight dye 649 (Pierce) labeled anti-VLA1 antibodies.

The results in Figure 8 show that the collagen XIII blocking antibody Ab2 does indeed significantly reduce the transmigration of VLA-1-positive monocytes from the upper chamber to the lower chamber in the transwell migration assay. The results for three independent transwell assays are summarized in Table 1. While the total numbers of VLA1-positive monocytes in the migrated population varies from one experiment to another, the percent reduction observed in the Ab2-

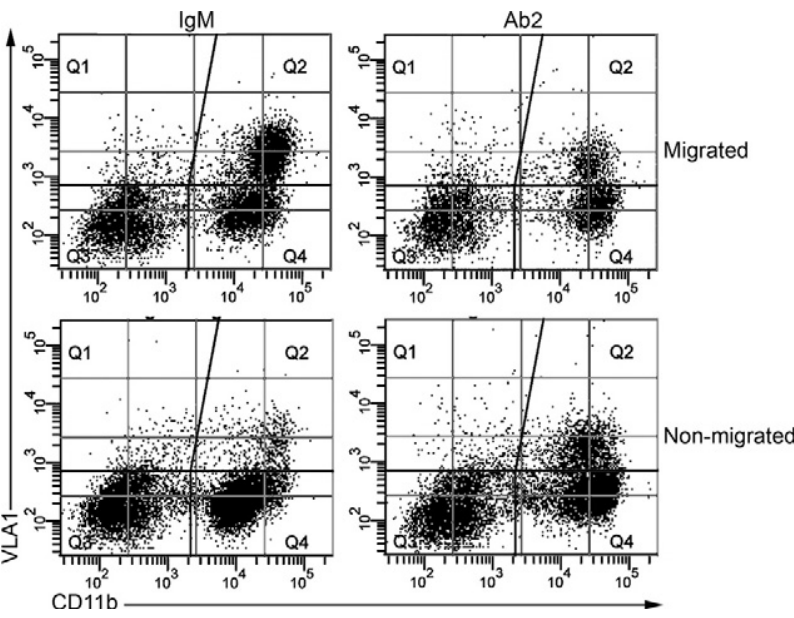

Figure 8. Neutralization of collagen XIII blocks transmigration of VLA1positive monocytes in transwell assays. Bone marrow derived leukocytes were subjected to biopanning on plates coated with anti-VLA1 antibodies. The panned cells were mixed with either anti-collagen XIII neutralizing antibodies (Ab2) or isotype matched control antibodies (IgM) and then added to the top layer of transwells coated with a monolayer of irradiated embryonic fibroblasts, and allowed to migrate for 14 hours. Cells were collected from the top (nonmigrated) and the bottom (migrated) compartments of the chamber and analyzed by dual-fluorescence-activated cell sorting for both CD11b (abscissa) and VLA1 (ordinate). The dual immunofluorescent VLA1-positive monocyte population in Q2 shows a clear reduction in this population in the Ab2-treated cells compared with cells treated with the isotype control mAb. Ab2 reduced VLA1 migration by $40.3 \% \pm 1.7 \%$ over three independent transwell experiments (see Table 1).

treated wells compared to the isotype matched nonreactive control wells was highly consistent $(40.3 \% \pm$ $1.7 \%)$. This selective migration was also observed in the upper chamber, where there were consistently more VLA1-positive cells in the Ab2 treated samples relative to $\lg \mathrm{M}$ controls.

\section{Discussion}

Earlier work from this and other laboratories have clearly implicated a role for $\alpha 1 \beta 1$ integrin in chronic inflammatory diseases. The work was initiated in studies using the Alport mouse model, ${ }^{6}$ and expanded to include models for chronic inflammatory bowel disease, ${ }^{31}$ rheumatoid arthritis, ${ }^{32}$ psoriasis, ${ }^{33}$ crescentic nephritis, ${ }^{34}$ and antiThy1 nephritis. ${ }^{35}$ It has been proposed that the mechanism underlying the observed reduction in inflammatory response when using a blockade of $\alpha 1 \beta 1$ integrin is due

Table 1. Collagen XIII-Blocking Antibodies (Ab2) Reduce Migration of VLA1-Positive Monocytes in Transwell Assays

\begin{tabular}{cccccr}
\hline & \multicolumn{2}{c}{ Migrated } & & \multicolumn{2}{c}{ Nonmigrated } \\
\cline { 2 - 3 } Expt & \multicolumn{1}{c}{$\operatorname{lgM}$} & \multicolumn{1}{c}{ Ab2* } & & $\operatorname{lgM}$ & \multicolumn{1}{c}{ Ab2 } \\
\hline 1 & $46.4 \pm 3.2$ & $28.9 \pm 1.7$ & & $7.7 \pm 0.8$ & $9.0 \pm 0.7$ \\
2 & $38.6 \pm 2.2$ & $21.7 \pm 1.1$ & & $6.7 \pm 0.2$ & $13.4 \pm 1.7$ \\
3 & $27.5 \pm 2.1$ & $16.7 \pm 0.9$ & & $11 \pm 0.8$ & $18.1 \pm 0.2$ \\
\hline
\end{tabular}

VLA1-positive monocytes (Q2 in scatter plots) are expressed as the percentage of total monocytes (Q2 plus Q4) in both migrated (lower chamber) and non-migrated (upper chamber) cell populations.

${ }^{*} \mathrm{Ab} 2$ reduced VLA1 migration by $40.3 \% \pm 1.7 \%$ over three independent transwell experiments. 
to blocking the selective recruitment of $\alpha 1 \beta 1$ integrinpositive peripheral blood leukocytes into the interstitial spaces of inflammatory tissues. Neutralizing antibodies against $\alpha 1 \beta 1$ integrin are being actively explored for their therapeutic potential in this regard. ${ }^{36}$ The cellular mechanism underlying this putative selective recruitment, however, has remained unknown. In this study, we show that collagen XIII is induced on the vascular endothelium of Alport kidneys. Using phage display, we identified the binding site on collagen XIII for $\alpha 1 \beta 1$ integrin. Blocking antibodies against this site block adhesion of $\alpha 1 \beta 1$ integrin-positive monocytes to collagen XIII in vitro, attenuate monocyte recruitment to the interstitial spaces of Alport kidneys in vivo, and inhibit transmigration of VLA1-positive monocytes in transwell assays. Based on these findings, we conclude that the cellular mechanism of $\alpha 1 \beta 1$ integrin-selective recruitment of leukocytes and monocytes to inflammatory tissues is mediated through adhesion of VLA1-positive circulating peripheral immune cells to collagen XIII, which is induced on the vascular endothelium at the site of inflammation.

Induction of ligands for specific integrins on vascular endothelium under the influences of an inflammatory response are well documented. Vascular cell adhesion molecule-1 and intercellular adhesion molecule- 1 are induced on the vascular endothelium at inflammatory sites, and direct selective recruitment of leukocytes expressing $\alpha 4 \beta 1$ and $\alpha\left\llcorner\beta 2\right.$ integrins, respectively, ${ }^{14}$ for example. These interactions represent the principal mechanism for recruitment of leukocytes/monocytes to inflammatory sites, and thus inhibitors of these interactions have been pursued as therapeutics for chronic inflammatory diseases. ${ }^{20,21}$ This work provides a new example of vascular endothelial induction of a ligand that selectively binds a subset of peripheral blood leukocytes/monocytes. The data supports that binding directs selective recruitment of these cells to the interstitial sites of inflammation, however, the cellular mechanisms underlying collagen XIII induction on the vascular endothelium, and the activation of leukocytes/monocytes on binding to collagen XIII remain to be elucidated. An alternate explanation of the data presented is that the interstitial monocytes become activated and then up-regulate $\alpha 1 \beta 1$ integrin, which may serve to retain these cells in the interstitial space.

Collagen XIII is a member of a group of transmembrane collagens. Expression of collagen XIII is fairly widespread. ${ }^{29}$ It is known to interact with $\alpha 1 \beta 1$ integrin receptors via the I domain of the $\alpha 1$ integrin subunit, ${ }^{28}$ and to induce receptor signaling, however the significance of this interaction has remained elusive. ${ }^{22}$ Deletion of collagen XIII is embryonic lethal. ${ }^{30}$ In addition to $\alpha 1$ integrin binding, the $150 \mathrm{~nm}$ rod-like ectodomain has been reported to preferentially bind heparin, fibronectin, Nidogen-2 and Perlecan. ${ }^{28,37}$ Collagen XIII has been hypothesized to play a key role in cell-cell as well as cell-matrix interactions involved in angiogenesis and neuronal development. ${ }^{30}$ The functional significance of collagen XIII expression on the vascular endothelium beyond its potential role in angiogenesis was never explored. Our data show that one function of this inducible transmembrane collagen is to direct the efflux of specific subsets of monocytes/leukocytes into interstitial spaces in chronic inflammatory disease responses.

Several lines of investigation have suggested that neutralization of $\alpha 1 \beta 1$ integrin may be useful in the treatment of chronic inflammatory diseases. These studies were performed using both neutralizing antibodies against $\alpha 1 \beta 1$ integrin as well as integrin $\alpha 1$-null mice, and have included models for kidney disease, lung disease, colitis, and arthritis. ${ }^{6,31-35,38-40}$ These studies provided the rational to develop humanized $\alpha 1 \beta 1$ integrin-neutralizing antibodies as a therapeutic agent for treating chronic inflammation and fibrosis. The cellular mechanism(s) underlying the therapeutic benefit appear to be multifaceted and have not been adequately addressed, although both cell proliferation and selective adhesion/transmigration have been suggested to play a role. ${ }^{31,41,42}$ Our studies identify collagen XIII as the induced ligand for $\alpha 1 \beta 1$ integrin-positive monocyte/leukocytes on the vascular endothelium. Based on selective recruitment of $\alpha 1 \beta 1$ monocytes in the fibrosing Alport kidney, and the preponderance of $\alpha 1 \beta 1$ monocytes in migrated cells shown in transwell migration assays, it appears the $\alpha 1 \beta 1$ integrin/ collagen XIII interaction mediates monocyte activation and extravagation into the interstitial spaces. This is a key event driving fibrosis, since monocytes are known to drive tubular epithelial cell apoptosis and promote the genesis of myofibroblasts, two hallmarks of progressive fibrosis. ${ }^{7,43}$ The fact that neutralizing antibodies block the interaction suggests that these antibodies alone, or in combination with integrin $\alpha 1$ neutralizing antibodies, may provide a potent therapeutic strategy for diseases where collagen XIII is induced on the vascular endothelium and selective influx of $\alpha 1 \beta 1$ integrin-positive leukocytes is observed.

It is important to note that while neutralizing antibodies against collagen XIII had a significant effect on fibrosis; it did not significantly reduce glomerular sclerosis and did not extend lifespan in Alport mice. This is very similar to what was reported for Alport mice on a Rag- 1 knockout background, which also blocked recruitment of leukocytes to the interstitium and also reduced fibrosis. ${ }^{44}$ Our observation underscores earlier work that suggests a specific role for $\alpha 1 \beta 1$ integrin in glomerular pathogenesis in Alport syndrome, which is distinct from its function in tubulointerstitial pathogenesis. ${ }^{6,45}$

\section{Acknowledgments}

We thank John (Skip) Kennedy for help in figure preparation, Mona Hansen for secretarial assistance, and Philip Gotwals of Biogen-Idec for the gift of VLA1 neutralizing antibodies.

\section{References}

1. Barker D, Hostikka SL, Zhou J, Chow LT, Oliphant AR, Gerkin SC Gregory MC, Skolnick MH, Atkin CL, Tryggvasson K: Identification of mutations in the COL4A5 collagen gene in Alport syndrome. Science 1990, 348:1224-1227 
2. Lemmink HH, Mochizuki T, van den Heuvel LPWJ, Schroder $\mathrm{CH}$, Barrientos A, Monnens LAH, van Oost BA, Brunner HG, Reeders ST, Smeets HJM: Mutations in the type IV collagen $\alpha 3$ (COL4A3) gene in autosomal recessive Alport syndrome. Hum Mol Gen 1994, 3:1269-1273

3. Mochizuki T, Lemmink HH, Mariyama M, Antignac C, Gubler M-C, Pirson Y, Verellen-Dumoulin C, Chan B, Schroder $\mathrm{CH}$, Smeets $\mathrm{HJ}$, Reeders ST: Identification of mutations in the $\alpha 3(\mathrm{IV})$ and $\alpha 4(\mathrm{IV}) \mathrm{col}$ lagen genes in autosomal recessive Alport syndrome. Nat Genet 1994, 8:77-81

4. Cosgrove D, Meehan DT, Grunkemeyer JA, Kornak JM, Hunter WJ, Samuelson GC: Collagen COL4A3 knockout: a mouse model for autosomal Alport syndrome. Genes Dev 1996, 10:2981-2992

5. Miner JH, Sanes JR: Molecular and functional defects in kidneys of mice lacking collagen $\alpha 3(\mathrm{IV})$ : implications for Alport syndrome. J Cell Biol 1996, 135:1403-1413

6. Cosgrove D, Rodgers K, Meehan D, Miller C, Bovard K, Gilroy A, Gardner H, Kotelianski V, Gotwasl P, Amatucci A, Kalluri R: Integrin alpha1beta1 and transforming growth factor-beta1 play distinct roles in Alport glomerular pathogenesis and serve as dual targets for metabolic therapy. Am J Pathol 2000, 157:1649-1659

7. Rodgers KD, Rao V, Meehan DT, Fager N, Gotwals P, Ryan ST, Koteliansky V, Nemori R, Cosgrove DE: Monocytes may promote myofibroblast accumulation and apoptosis in Alport renal fibrosis. Kidney Int 2003, 63:1338-1355

8. Kitagawa K, Wada T, Furuichi K, Hashimoto H, Ishiwata Y, Asano M, Takeya M, Kuziel WA, Matsushima K, Mukaida N, Yokoyama H: Blockade of CCR2 ameliorates progressive fibrosis in kidney. Am J Pathol 2004, 165:237-246

9. Chow F, Ozols E, Nikolic-Paterson DJ, Atkins RC, Tesch GH: Macrophages in mouse type 2 diabetic nephropathy: correlation with diabetic state and progressive renal injury. Kidney Int 2004, 65:116-128

10. Sampson NS, Ryan ST, Enke DA, Cosgrove D, Koteliansky V, Gotwals $P$ : Identification of a role for alpha1 integrin in renal pathogenesis using global analysis of gene expression. J Biol Chem 2001, 276:34182-34188

11. Gardner H, Kreidberg J, Koteliansky V, Jaenisch R: Deletion of integrin $\alpha 1$ by homologous recombination permits normal murine development but gives rise to a specific deficit in cell adhesion. Dev Biol 1996, 175:301-313

12. Pozzi A, Wary KK, Giancotti FG, Gardner HA: Integrin $\alpha 1 \beta 1$ mediates a unique collagen-dependent proliferation pathway in vivo. J Cell Biol 1998, 142:587-594

13. Hogg N, Henderson R, Leitinger B, McDowall A, Porter J, Stanley P: Mechanisms contributing to the activity of integrins on leukocytes. Immunol Rev 2002, 186:164-171

14. Springer TA: Traffic signals on endothelium for lymphocyte recirculation and leukocyte emigration. Annu Rev Physiol 1995, 57:827-872

15. Jung U, Norman KE, Scharffetter-Kochanek K, Beaudet AL, Ley K: Transit time of leukocytes rolling through venules controls cytokineinduced inflammatory cell recruitment in vivo. J Clin Invest 1998, 102: $1526-1533$

16. Jones TR, Nozomu S, Adams AB, Pearson TC, Larsen CP: Intravital microscopy identifies selectins that regulate $\mathrm{T}$ cell traffic into allografts. J Clin Invest 2003, 112:1714-1723

17. Correale J, Bassani Molinas ML: Temporal variations of adhesion molecules and matrix metalloproteinases in the course of MS. J Neuroimmunol 2003, 140:198-209

18. Matias-Roman S, Galvez BG, Genis L, Yanez-Mo M, de la Rosa G, Sanchez-Mateos P, Sanchez-Madrid F, Arroya AG: Membrane type 1-matrix metalloproteinase is involved in migration of human monocytes and is regulated through their interaction with fibronectin or endothelium. Blood 2005, 105:3956-3964

19. Hynes RO: Integrins: versatility, modulation, and signaling in cell adhesion. Cell 1992, 69:11-25

20. Harlan JM, Winn RK: Leukocyte-endothelial interactions: clinical trials of anti-adhesion therapy. Crit Care Med 2002, 30:S214-S219

21. Szekanecz Z, Koch AE: Therapeutic inhibition of leukocyte recruitment in inflammatory diseases. Curr Opin Pharmacol 2004, 19: 423-428

22. Dickeson SK, Mathis NL, Rahman M, Bergelson JM, Santoro SA: Determinants of ligand binding specificity of the alpha(1)beta(1) and alpha(2)beta(1) integrins. J Biol Chem 1999, 274:32182-32191

23. Jokinen J, Dadu E, Nykvist P, Kapyla J, White DJ, Ivaska J,
Vehvilainen P, Reunanen H, Larjava H, Hakkinen L, Heino J: Integrinmediated cell adhesion to type I collagen fibrils. J Biol Chem 2004, 279:31956-31963

24. Dong QG, Bernasconi S, Lostaglio S, De Calmanovici RW, MartinPadura I, Breviario F, Garlanda C, Ramponi S, Mantovani A, Vecchi A: A general strategy for isolation of endothelial cells from murine tissues. Characterization of two endothelial cell lines from the murine lung and subcutaneous sponge implants. Arterioscler Thromb Vasc Biol 1997, 17:1599-1604

25. Mendrick DL, Kelly DM, duMont SS, Sandstrom DJ: Glomerular epithelial and mesangial cells differentially modulate the binding specificities of VLA-1 and VLA-2. Lab Invest 1995, 72:367-375

26. Shaner NC, Campbell RE, Steinbach PA, Giepmans BN, Palmer AE, Tsien RY: Improved monomeric red, orange and yellow fluorescent proteins derived from Discosoma sp. Red fluorescent protein. Nature Biotechnol 2004, 22:1524-1525

27. Luby-Phelps K: Preparation of fluorescently labeled dextrans and ficolls. Methods Cell Biol 1989, 29:59-73

28. Nykvist P, Tu H, Ivaska J, Kapyla J, Pihlajaniemi T, Heino J: Distinct recognition of collagen subtypes by alpha(1)beta(1) and alpha(2)beta(1) integrins. Alpha(1)beta(1) mediates cell adhesion to type XIII collagen. J Biol Chem 2000, 275:8255-8261

29. Hagg P, Vaisanen T, Tuomisto A, Rehn M, Tu H, Huhtala P, Eskelinen S, Pihlajaniemi T: Type XIII collagen: a novel cell adhesion component present in a range of cell-matrix adhesions and in the intercalated discs between cardiac muscle cells. Matrix Biol 2001, 19:727-742

30. Sund M, Ylonen R, Tuomisto A, Sormunen R, Tahkola J, Kvist AP, Kontusaari S, Autio-Harmainen $\mathrm{H}$, Pihlajaniemi T: Abnormal adherence junctions in the heart and reduced angiogenesis in transgenic mice overexpressing mutant type XIII collagen. EMBO J 2001, 20:5153-5164

31. Krieglstein CF, Cerwinka WH, Sprague AG, Laroux FS, Grisham MB, Koteliansky VE, Senninger N, Granger DN, de Fougerolles AR: Collagen-binding integrin alpha 1 beta 1 regulates intestinal inflammation in experimental colitis. J Clin Invest 2002, 110:1773-1782

32. de Fougerolles AR, Sprague AG, Nickerson-Nutter CL, Chi-Rosso G, Rennert PD, Gardner H, Gotwals PJ, Lobb RR, Koteliansky VE: Regulation of inflammation by collagen-binding integrins $\alpha 1 \beta 1$ and $\alpha 2 \beta 1$ in models of hypersensitivity and arthritis. J Clin Invest 2000, 105:721-729

33. Conrad C, Boyman CC, Tonel G, Tun-Kyi A, Laggner U, de Fougerolles A, Kotelianski V, Gardner H, Nestle FO: Alpha1beta1 integrin is crucial for accumulation of epidermal T cells and the development of psoriasis. Nat Med 2007, 13:836-842

34. Cook HR, Khan SB, Allen A, Bhangal G, Smith J, Lobb RR, Pusey CD: Treatment with an antibody to VLA-1 integrin reduces glomerular and tubulointerstitial scarring in a rat model of crescentic glomerulonephritis. Am J Pathol 2002, 161:1265-1272

35. Kagami S, Urushihara M, Kondo S, Hayashi T, Yamano H, Loster K, Vossmeyer D, Reutter W, Kuroda Y: Effects of anti-alpha1 integrin subunit antibody on anti-Thy-1 glomerulonephritis. Lab Invest 2002 82:1219-1227

36. McCall-Culbreath KD, Zutter MM: Collagen receptor integrins: rising to the challenge. Current Drug Targets 2008, 9:139-149

37. Tu H, Sasaki T, Snellman A, Gohring W, Pirila P, Timpl R, Pihlajaniemi $\mathrm{T}$ : The type XIII collagen ectodomain is a 150-nm rod and capable of binding fibronectin, nidogen-2, perlecan, and heparin. J Biol Chem 2002, 277:23092-23099

38. Abraham WM, Ahmed A, Serebriakov I, Carmillo AN, Ferrant J, de Fougerolles AR, Garber EA, Gotwals PJ, Koteliansky VE, Taylor F, Lobb RR: A monoclonal antibody to $\alpha 1 \beta 1$ blocks antigen-induced airway responses in sheep. Am J Respir Crit Care Med 2003, 169:97-104

39. Ray SJ, Franki SN, Pierce RH, Dimitrova S, Koteliansky V, Sprague AG, Doherty PC, de Fougerolles AR, Topham DJ: The collagen binding alpha1beta1 integrin VLA-1 regulates CD8 T cell-mediated immune protection against heterologous influenza infection. Immunity 2004, 20:167-169

40. Ben-Horin S, Bank I: The role of very late antigen-1 in immunemediated inflammation. Clin Immunol 2004, 113:119-129

41. Meharra EJ, Schon M, Hassett D, Parker C, Havran W, Gardner H: Reduced gut intraepithelial lymphocytes in VLA-1 null mice. Cell Immunol 2000, 201:1-5 
42. Andreasen SO, Thomsen AR, Koteliansky VE, Novobrantseva TI, Sprague AG, de Fougerolles AR, Christensen JP: Expression and functional importance of collagen-binding integrins, alpha beta 1 and alpha 2 beta 1, on virus-activated T cells. J Immunol 2003, 171:2804-2811

43. Duffield JS, Tipping PG, Kipari T, Caihier J-F, Clay S, Lang R, Bonventre J, Hughes J: Conditional ablation of macrophages halts progression of crescentic glomerulaonephritis. Am J Pathol 2005, 167:1207-1219
44. LeBleu VS, Sugimoto H, Miller CA, Gattone VH, Kalluri R: Lymphocytes are dispensable for glomerulonephritis but required for renal interstitial fibrosis in matrix defect-induced Alport renal disease. Lab Invest. 2008, 88:284-292

45. Cosgrove D, Meehan DT, Pozzi A, Chen X, Rodgers KD, Tempero RM, Delimont D, Zallocchi M, Rao VH: Integrin $\alpha 1 \beta 1$ regulates MMPs via p38 MAPkinase in mesangial cells: implications for Alport syndrome. Am J Pathol 2008, 172:761-773 